\title{
Empirical Research on Reading Teaching of College English from the Perspective of Metacognitive Theory
}

\author{
Dan Cao \\ Xijing University, Xi’an, 710000, China
}

Keywords: Reading teaching, College English, Metacognitive theory

\begin{abstract}
Metacognitive theory plays an important role in the reading teaching of College English. Based on the metacognitive theory, the guidance and training of students can make English reading teaching work twice the result with half the effort. This paper takes the non-English Majors of Xijing University as the research object, and sets up the comparison of English scores between the experimental group and the control group. The results show that metacognitive theory plays a significant role in improving the effectiveness of College English reading teaching.
\end{abstract}

\section{Introduction}

Flavell, a professor of psychology in America, first proposed metacognitive theory. He holds that metacognition refers to the self-awareness and self-regulation of cognitive activities. After a long period of development, metacognition has gradually developed into a new research field in cognitive psychology. Chinese scholars have also conducted extensive research on metacognitive theory and metacognitive learning strategies, focusing on metacognitive theory, metacognitive theory and English teaching. Research on the theory of metacognition and English teaching involves the application of metacognitive strategies in English listening, reading, speaking in the discussion this paper focuses on the University of metacognitive theory in English reading teaching. Reading is a very important part in College English class, and occupies a pivotal position in all kinds of language tests. In effective reading, the reader must have certain control over their cognitive activities and processes, and actively understand them according to the textual information. It is this active activity that makes reading become the object of metacognition research. In the process of development only decades of metacognition, people gradually realize that the influence of metacognitive theory on the aspects of people's lives, especially the impact on reading, for College English reading teaching, the research and application to improve the students' English reading ability to obtain information has a significant impact on reading ability. At the same time, with the popularity of metacognitive theory, reading can improve people's quality of life and enhance people's ability to obtain information. Therefore, it is of great significance to strengthen the application of metacognitive theory in English reading. Metacognition is the cognitive subject's cognition of cognitive phenomena. This cognition can be the cognition of the cognitive subject to his or her current cognitive behavior, or the understanding of his current cognition or emotional state.

\section{Metacognitive Theory and Reading Teaching of College English}

Summary of Metacognitive Theory. With the acceptance and development of most psychologists, the theory of metacognitive concept also gradually enriched and developed, but no matter what psychology explanation is the metacognitive knowledge and regulation of cognition based on two aspects. Specifically, metacognition is cognition about cognition, knowledge of cognitive ability and cognitive process on the body of its own, so the application of metacognition refers to the learning of their cognitive process, understanding the regulation ability thinking ability, and gradually a clear understanding of the limitations of self-cognition, the total speaking, there are 
two ways to display the metacognitive ability of self, one is the level of understanding of their cognitive ability, two is to know activity monitoring ability. The planning strategy refers to through the establishment of a detailed study plan, set a reasonable approach to learning, actively to carry out the necessary plan, including learning objectives, learning time, learning methods, learning effect evaluation and a series of study plan content monitoring strategy refers to the application of metacognitive strategies in learning the subject of their own learning process. The realization of learning goals in learning plan. To monitor and control the progress of the whole study, adjust or modify the unreasonable information timely and accurately, and timely feedback the effective information. The evaluation method of learning strategy is that the body of their own learning goals, learning progress, learning achievement evaluation, are evaluated, can effectively supervise their learning progress smoothly, the problems of correct regulation strategy refers to learning ontology according to their own set of learning plans, learning objectives, learning from the target there are plans in the current new situation and does not apply for the phenomenon of the necessary learning schedule adjustment, so as to achieve the goal of learning plan.

Current Situation of Reading Teaching of College English. The traditional teaching model of English reading is teacher centered, and classroom activities are teachers speaking students' records. The focus of classroom learning lies in the analysis of words and sentences, analyzing the grammatical structure of the teachers, too much emphasis on grammar in reading teaching, the teaching process arrangement of words in practice, analysis is also heavy and difficult to sentence these sentences to explain words, syntax analysis. A single teaching method, students feel no interest in this kind of error, the teacher teaching idea, most of the students in reading, do not know how to effectively understand and inductive analysis, this paper makes, but deliberately to the analysis and translation of difficult sentences, the lack of interaction between teachers and students, quite a part of the students' classroom participation is not high, gradually lose interest in English reading class. A passive learning attitude and method, the subjective initiative is limited, can greatly improve the reading level. Most of the students in middle school have relatively fixed reading habits, love word for word and sentence for sentence to read, rather than by the sentence group, meaning group to read, so the lack of understanding of the subject of the article, the lack of internal logic relations between paragraphs and paragraphs understanding, not from the macro grasp the reading on the reading materials request. Test oriented English teaching pays more attention to grammar teaching, but there is no high requirement for the expansion of vocabulary. Students' reading speed is proportional to the size of their vocabulary. The vocabulary is large, the new words encountered in reading are few, the reading speed is quick, otherwise it is slow. After entering the University, the difficulty of the reading material is gradually increasing, more and more new words encountered in reading, reading more and more slowly, the students' reading more and more difficult, undoubtedly put forward higher requirements on College English reading teaching.

Reading Teaching Model of College English Based on Metacognitive Theory. The application of metacognitive theory to college English reading is very important, this is not only reflected in the improvement of College English reading, to cultivate students' initiative of English reading, for life after the accumulation of an asset. Therefore, the application of metacognitive theory should be strengthened in the teaching of College English reading. On the one hand is the need to improve the effectiveness of College English reading teaching, research and application of university English reading teaching has an important influence on improving students' English reading ability, the ability to obtain active reading information, in this way can cultivate students' English reading skills, reading strategies, reading comprehension ability. On the other hand, it can guide the students to study actively, which is beneficial to the cultivation of students' metacognitive awareness, and lays a foundation for improving the ability of reading comprehension to improve the effect of English learning. English reading is a unique process of cognitive development of college students, in the cognitive process, from word recognition, translation, sentence understanding, to split the whole article structure, are closely related with a series of meta cognitive activities. English reading comprehension is a process in which students understand English texts gradually and understand English texts gradually. According to a questionnaire data analysis, high level English readers have 
high meta cognitive ability, high levels of so-called means in College English reading test. Therefore, there is a positive correlation between the level of English reading and metacognitive strategies.

\section{Empirical Analysis on Reading Teaching of College English from the Perspective of Metacognitive Theory}

Experiment Arrangement. The investigation and the subjects of Xijing University grade 2016 non-English majors, they come from the 15 professional as the starting point of the English teaching class, experiment began their school after the third semester, the end of the semester they will participate in the National College English test band four. Before the experiment they participated in a total of three formal English exam, from the above five classes (about 270 people) every time the exam score of reading about the worst of the $25 \%$ screen, where two or more than two times were selected (60) as experimental object. In accordance with the principle of convenience, according to the class, they were divided into experimental group and control group (30 each). The two group is described in the following table.

Table 1. Experimental group and control group

\begin{tabular}{|c|c|c|c|c|}
\hline Group & Number & Mean age & Male & Female \\
\hline Experimental group & 30 & 20.1 & 19 & 11 \\
\hline Control group & 30 & 19.8 & 20 & 10 \\
\hline
\end{tabular}

The questionnaire on the use of metacognitive strategies and reading strategies before and after the experiment is divided into three parts: the first part is the personal profile. The second part is the basic situation of the reading, consists of six questions, related to the importance of reading in English learning, reading purpose, preferences, access ways, main obstacle material reading and reading method. To strengthen the effect of strategy training, the experimental group members required to submit a weekly report every day for reading experience, the time to learn English, especially in English reading and reading strategy use practice experience, complete the task of reading progress. At the same time, individual interviews during weekly intervals provided the experimental group members with metacognitive awareness and strategy use, as well as the existing problems. The experiment lasted for ten weeks, and the experimental group received four extra-curricular intensive training, arranged in first, third, sixth and nine weeks, 30-40 minutes each time. It first introduces metacognitive knowledge and its role in autonomous learning; knowledge about the subject of cognition; reading tasks in training programs; writing requirements for weekly reading experiences; and so on. The second time to help students evaluate their progress in reading and analyze the existing problems; focus on answering questions raised by students on how to solve the problem of new words in reading. In the third comparison, the results of the two tests were used to guide the further differentiation of metacognitive strategies and reading strategies, and to reiterate the role and significance of metacognitive strategy training. The last time the guidance from about ten days after the experiment, summary and evaluation of the stage of training, summed up the various strategies of nearly 40 students in the reading of the report, and to encourage students to continue to try various strategies after the training, to promote English learning.

Experiment Results. The pretest data collection mainly comes from the questionnaire survey of the experimental group. Post test data were collected from questionnaires including experimental group and control group; the two group in the final examination scores of reading comprehension test; open questions in the questionnaire, experimental group reading reports and the students of the two groups of individual interviews. Quantitative and qualitative analysis of the collected data was conducted in this study. The experimental group pretest and posttest questionnaire data to measure the effect of using the strategy of training before and after the paired sample t test; the two-group posttest questionnaire and reading test data respectively through independent sample t test to compare the two groups of students in training after the reading strategy use and difference of performance. The answers to the second questions in the questionnaire, the reading training experience of the subjects, and the interviews with the subjects, ideas, hobbies and basic situations may also have some 
explanatory power on the training effect. At the end of the experiment, the two groups took part in the final English examination (grade four), and the scores of the reading comprehension items were collected and analyzed as the posttest data. After the independent sample t test of the two groups of reading scores, it was found that the average score of the experimental group was higher than that of the control group.

Table 2. Reading scores of experimental group and control group

\begin{tabular}{|l|r|r|r|r|}
\hline & Number & Mean score & \multicolumn{1}{|c|}{$\begin{array}{c}\text { Standard } \\
\text { deviation }\end{array}$} & \multicolumn{1}{|c|}{$\mathrm{t}$} \\
\hline $\begin{array}{l}\text { Reading score of } \\
\text { experimental group }\end{array}$ & 30 & 33.552 & 3.254 & \multirow{2}{*}{1.863} \\
\cline { 1 - 2 } $\begin{array}{l}\text { Reading score of } \\
\text { control group }\end{array}$ & 30 & 29.412 & 6.116 & \\
\hline
\end{tabular}

Results Discussion. In the process of College English teaching, teachers should create an environment and atmosphere for students to communicate and read skills equally. In this atmosphere, students can truly understand their own university English reading, free to discuss with each other, at the same time, English teachers are conscious guide, and analyze the application of metacognitive theory related, this atmosphere, is conducive to the formation of a heated discussion in the atmosphere, more likely to agree the result of the discussion, has a significant impact for the application of metacognitive strategies in College English reading. In addition, in the discussion, for the problem of College English reading students, teachers should give the necessary attention, and to answer according to the meta cognitive concept, to improve the status of metacognitive strategies in the minds of students, and encourage students to consider their own environment, meta cognitive theory to choose the suitable characteristic, thus the students actively occupy the dominant position in College English learning, the teacher should be in the classroom, and actively create a sense of application of cognitive strategies metacognitive knowledge cultivation and element of the atmosphere, the atmosphere let students feel the same, to the use of metacognitive strategies in conscious reading, let the students after learn and benefit, realize the value maximization of reading teaching, metacognitive strategy teaching advantages.

\section{Conclusion}

The students with poor reading performance are not familiar with the reading strategies. Although metacognitive reading strategies are used, metacognitive strategies are usually not used. These students generally have a positive attitude towards strategy training. The short-term strategy training has a significant effect on promoting the use of metacognitive strategies and strengthening the use of reading strategies, but it has not produced a very significant effect on the rapid improvement of reading performance. These conclusions may have some implications for College English teaching.

\section{References}

[1] Dai Qing'e, Zheng Yan. An Empirical Study of the Meta-cognitive Application of the Flipped Classroom Model in College English [J]. Journal of Ningbo University (Educational Science Edition), 2016, 38(5): 95-99.

[2] Xue Lanhua. On the Teaching of College English Reading Teaching under the Meta Cognitive Theory [J]. Journal of HUBEI Correspondence University, 2016, 29(17): 141-142.

[3] Zhang Yan. Metacognitive theory and college English reading teaching [J]. Journal of Nanchang College of Education, 2011, 26(5): 152+157.

[4] Liu Ying. A Study of Effectiveness on EFL Reading Metacognitive Strategy Training [J]. Foreign Languages and Their Teaching, 2009(10): 38-41. 